\title{
The Effect of Alternative Measures of Distance on the Correlation of Real Effective Exchange Rate Returns: An Approach to Contagion Analysis
}

\author{
Jean Coulom ${ }^{1}$ and Vijay Shenai ${ }^{2, *}$ \\ 1 Independent Researcher, University of Westminster, London W1W 7BY, UK; jeancoulom@hotmail.fr \\ 2 Independent Researcher, University of Lincoln, Lincoln LN6 7TS, UK \\ * Correspondence: kvshenai11@gmail.com
}

Received: 14 August 2018; Accepted: 10 October 2018; Published: 12 October 2018

\begin{abstract}
The topic of contagion has gained importance in the last few decades, earning its place amongst the most debated topics in international economics. Contagion is a phenomenon where market disturbances in crisis times are observed to spread from one country to the other in the form of comovements in exchange rates, stock prices, bond spreads, capital and trade flows. Analysing contagion and, more important, being able to make an on-coming prediction successfully helps economic planners to take appropriate rectificatory action toward establishing stable macroeconomic conditions. In previous studies, various proxies for distance have been used to test their explanatory power on a suitable dependent variable, typically a crisis index. In this paper, the separate impacts of geographic distance, psychic distance and cultural factors are tested on the correlation of real exchange rate returns to assess their predictive power. Using a sample of 30 countries for a period of 24 years (1993 to 2016) and data at monthly intervals, a panel regression is conducted. The findings of the analysis are that there is a negative effect of all the three explanatory variables on the correlation of real exchange rate returns. Moreover, a rolling regression conducted across the whole period shows coefficients going back to zero just before a crisis event and tending to fall afterwards. These findings contribute to the literature on contagion analysis by taking a different approach and exploring the separate impacts of geographic distance, psychic distance and cultural factors as explanatory variables and assessing their predictive power. The findings of the research are thus useful for policy makers towards restoring stable economic conditions.
\end{abstract}

Keywords: financial crises; contagion; open economy macroeconomics

JEL Classification: F32; F410; O19

\section{Introduction}

The purpose of this section is to present the background of the research, aim and objectives, and the plan of research.

\subsection{Background}

An exchange rate represents the amount of one currency necessary to buy another currency. Nominal effective exchange rates (NEER) represent the value of one currency against a basket of currencies. The real effective exchange rate (REER) is the nominal effective exchange rate with the addition of taking inflation into account by using the consumer price index (CPI) of the country under research against a basket of consumer price indices of the trading partners. Data on real effective exchange rates of all countries is widely available; this research uses the Bruegel database for its 
frequent updates and its wide period of monthly data. Previous studies have used the correlation of real effective exchange rate returns as a measure of contagion and a measure of the degree of importance of the relationship between countries. Indeed, they showed that the correlation of real effective exchange rates which represents the 'strength' of the link between two real effective exchange rates of two countries also represents, by extension, a measure of the link between two countries. These studies allowed for distance in different ways but did not specifically allow separately for geographic, psychic or cultural similarities. Therefore, based on other studies suggesting that a more complete vision of distance should include cultural aspects: psychic distance factors and Hofstede factors are used in this research with a wider range of dates and countries to present a larger picture of the effects.

\subsection{Aim and Objectives}

The aim of this research is to assess the extent to which geographical distance and alternative concepts of distance such as psychic distance and cultural distance can be predictors of contagion.

There are two main objectives to this research:

(1) To examine the impact of geographic, psychic and cultural distance on the correlation of real effective exchange rate returns after a review of relevant previous research.

(2) To assess the use of geographic, psychic and cultural distance as predictors of contagion.

\subsection{Plan of Research}

The rest of this research is organised as follows: Section 2 is a review of relevant literature. This part presents a critical review of the most relevant articles on the subject of this research. Overall, this section covers what contagion is, the correlation of real effective exchange rate returns, geographic distance, psychic distance, Hofstede factors, and the gravitational model. 3 presents the sources of the data and explains the choices made in term of sampling and methodology. 4 presents the regression analysis and the results that were found. 5 is a conclusion of the research and also outlines the limitations and recommendations for future research.

\section{Literature Review}

In this section, concepts and empirical research related to the subject of the current research are covered: the phenomenon of contagion, previous studies and findings on crisis and contagion, approaches to empirical research, gravitational models, geographic distance, psychic distance, cultural variables, the correlation of financial variables and real effective exchange rates.

\subsection{Crises and Contagions}

Although the term 'contagion' is a term brought widely into use to describe the crisis in Thailand in July 1997, which rapidly spread to neighbouring countries, it was clearly evident in many previous phenomena, recorded in history, such as the stock market crash in the US in 1929 which triggered the 'great depression'. Rigobon (2002) reported that economists mostly agree that contagion was evident in phenomenon such as: the "Mexican Tequila" effect of 1994, the "Asian Flu" of 1997, the "Russian Cold" of 1998, the "Brazilian sneeze" in 1999 and the "NASDAQ Rash" in 2000. However, he also said that there is no agreement on what contagion really is. Nowadays, you can easily add the global financial crisis of 2007, the European debt crisis of 2009 and the last Russian crisis in 2014.

The effects of contagion refer to the spread of market disturbances-from one country to the other, which can be observed through co-movements in exchange rates, stock prices, sovereign spreads, and capital flows (Dornbusch et al. (2000); Kaminsky and Reinhart (2000); Calvo (2004)). The adverse effect of contagion is that it creates volatility in financial markets and disrupts the economic systems of countries with spillover effects caused by the actions of governments, financial institutions, investors, and borrowers. 
In a crisis, exchange rates depreciate and real output falls in the country where the crisis originates and this spreads to neighbouring markets and trading partners. Crisis literature has also identified the importance of capital outflows. Periods of excessive capital outflows from countries (Calvo and Vegh (1999)) are used as a basis for identifying contagion.

Rigobon (2002) separate theories of contagion into two categories: "crisis-contingent" and "non-crisis-contingent" theories. The difference is that the latter assume that the mechanism of transmission are the same whether there is a crisis or not. Karolyi (2003), Moser (2003) and Masson (1999), and some branches of research look at the herd behaviour of investors modeled by information assymmetries unrelated to economic fundamentals implying irrational behaviour (Calvo and Mendoza (1999); Kumar and Persaud (2002)). Another perspective is to look at the effect on trade flows (Eichengreen et al. (1995); Glick and Rose (1999)). 'Positive' contagion is associated with herd inflow of capital, i.e., capital flows unrelated to fundamentals, particularly to emerging markets, whilst 'negative' contagion is related to rapid outflows of capital.

\subsection{Research Approaches on the Study of Contagion}

$\mathrm{Xu}$ (2008) reported three principal methods to conduct empirical studies on the subject of research on contagion: dichotomy, GARCH and correlation. Authors such as Eichengreen et al. (1995) or Kaminsky and Reinhart (2000) used a dichotomy method to research crises and contagion whereas Engle et al. (1990) used a GARCH model to research exchange rates volatility spill overs. King and Wadhwani (1990) were the first to research contagion by using correlation between stock returns. They were followed by other authors such as Baig and Goldfajn (2002) who used correlation to find evidence of contagion during the Asian crisis of 1997 or Corsetti et al. (2001) who discuss the methodology.

According to Bayoumi et al. (2007), correlation of a financial variable shows contagion because it increases during periods of heavy herding of investors. However only looking at the levels of correlation is troublesome for four reasons: first the approach is not a measure of prediction; second higher correlation is not always due to herd-behavior but could also be a reaction to a wide change in fundamentals (e.g., trade levels). Third, high correlation could simply be a consequence of large movements one after the other that Corsetti et al. $(2001,2005)$ identify as "periods of turmoil". Finally, correlations tend to increase over time which could blur the results. So, to get a clearer picture, there is justification to view the pattern of movements of the correlation of real exchange rate returns and to test for the separate impacts of alternative distance measures.

\subsection{Gravitational Model}

Academic literature on gravitational models is traditionally focused on trade flow.

The basic gravitational model in economics was born out of an analogy of Newton's universal gravitation theory. In the classical version of the gravitational model in economics, gross domestic products are the equivalent of the mass variables of the equation.

Ravenstein (1889) was the first author to use a gravity model, although it was to model migration flows. It was then Tinbergen (1962) who used the model to explain the flow of trade. From this starting point, the authors broadly used the gravity formula to make models of trade flows, foreign direct investments or even correlation between real effective exchange rates of country pairs. Bergamo and Pizzi (2014) used an equivalent gravity model on foreign direct investments and inspired this research initially. The classical gravitational model of foreign direct investment they used is as follows:

$$
F D I_{i, j}=\beta_{0} * \frac{G D P_{i}^{\beta_{1}} * G D P_{j}^{\beta_{2}}}{D_{i, j}^{\beta_{3}}}
$$

where $F D I$ is the volume of foreign direct investment from country $i$ to country $j, G D P_{i}$ and $G D P_{j}$ are the gross domestic products of the two countries and $D_{i, j}$ is a variable of distance between those two countries. With logarithmic transformations, the relation becomes: 


$$
F D I_{i, j}=\beta_{0}+\beta_{1} * \ln \left(G D P_{i}\right)+\beta_{2} * \ln \left(G D P_{j}\right)+\beta_{3} * \ln \left(D_{i, j}\right)
$$

The logic for using a distance variable in an investigation on contagion becomes clearer from the study of gravitational models.

Bayoumi et al. (2007) presented an alternative model for the correlation of real effective exchange rates that is based on the gravity model with modifications. For instance, they did not use the gross domestic products of the pair of countries, as independent variables, but the variance of returns and a vector of fundamentals. Indeed, Bayoumi et al. (2007) note that "the mass variable becomes irrelevant" if the correlation of real effective exchange rates is used as the dependent variable because there is almost no reason to believe that the size (e.g., gross domestic product) of a country has any relation to the correlation of the real effective exchange rates. On the other hand, there is a case for a link between gross domestic product and real effective exchange rates: a strong gross domestic product tends to be paired with a rising currency and therefore a rising exchange rate. This was verified by several authors, such as Rodrik (2008) who provided evidence that a high real effective exchange rate stimulates economic growth.

\subsection{Geographical Distance, Cultural Factors and Psychic Distance}

As seen in the previous part, the gravity model uses variable(s) of distance between countries. Initially, this distance was purely geographical with adjustments made from now and then by using dummy variables for realities such as common border or common language.

\subsection{Geographic Distance}

Loungani et al. (2002) find that physical or geographic distance has been found to be an important and extremely robust factor in a range of economic relationships. The measure used for geographic distance between countries in research is the 'Great Circle Distance' between the capital cities of two countries of interests. Physical distance is a typical variable in international trade studies using gravity model and often used to reflect the perception that geographically adjacent countries are more likely to share similarities than others. Sharing a common border and being in the common continental region may increase perceived closeness (Zhu et al.). Researchers in finance (Puy (2013)) have investigated the role of distance, through gravity models to analyse the determinants of cross-border financial stocks and flows and found that information asymmetries are well captured by geographic distance. In the contagion literature, geographic distance has been an important explanatory variable, as, trade and capital flows between two countries can be modeled as an increasing function of the size of the two economies, and decreasing in their cost of transport, measured by their distance.

\subsection{Hofstede and Cultural Dimensions}

Hofstede (1984) developed a theory of cultural dimensions as a framework for cross-cultural communication. The values of members of a society are influenced by the society's culture and these values in turn influence the behaviour of its members. In the final version of the theory (Hofstede (2011)), there are six culture dimensions (individualism-collectivism; uncertainty avoidance; power distance (strength of social hierarchy) and masculinity-femininity (task orientation versus person-orientation), long-term orientation (to cover aspects of values not discussed in the original paradigm) and indulgence versus self-restraint. Thus Hofstede's factors are composed of six dimensions that are used to assess the cultural proximity between countries. The dimensions are: 


\begin{tabular}{|c|c|}
\hline$H O F_{P D I}$ & Power distance \\
\hline$H O F_{I N D}$ & individualism \\
\hline$H O F_{M A}$ & Masculinity \\
\hline$H O F_{u}$ & Uncertainty avoidance \\
\hline & Long term orientation \\
\hline$\partial F_{I \Lambda}$ & Indulgence \\
\hline
\end{tabular}

More specifically, each factor is described further by Hofstede as in Table 1:

Table 1. Hofstede's cultural factors. Source: Hofstede website.

\begin{tabular}{ll}
\hline Power distance & $\begin{array}{l}\text { A high score means that the population of the country accept more that the power is } \\
\text { distributed unequally. }\end{array}$ \\
\hline Individualism & $\begin{array}{l}\text { The degree of individualism in the society. A high score means that the individuals are } \\
\text { more likely to take care of themselves and their direct family. }\end{array}$ \\
\hline Masculinity & $\begin{array}{l}\text { A high score means that the society is more likely to be driven by competition and } \\
\text { success. A low score means that the society is more likely to be driven by caring and } \\
\text { the quality of life. }\end{array}$ \\
\hline Uncertainty avoidance & $\begin{array}{l}\text { A high score means that the individuals of the country don't like surprises, planning } \\
\text { and structuring is at the utmost importance. }\end{array}$ \\
\hline Long term orientation & $\begin{array}{l}\text { A high score means that the society studied has a more pragmatic view on truth } \\
\text { (e.g., epends on the context and time) and therefore can adapt traditions to current } \\
\text { conditions whereas a low score means that traditions and norms are prevalent, } \\
\text { and changes are seen suspiciously. }\end{array}$ \\
\hline Indulgence & $\begin{array}{l}\text { A high score means a weak control over desires and impulses (e.g., indulgence) } \\
\text { whereas a low score means a stronger control (e.g., restraint). }\end{array}$ \\
\hline
\end{tabular}

The dimensions are compounded into a single factor named $H O F_{I N D E X}$.

\subsection{Psychic Distance}

Psychic distance was introduced by Beckerman (1956) as an explanation to why some countries felt "nearer" than others. Johanson and Vahlne (1977) defined it as: "the sum of factors preventing the flow of information from and to the market. Examples are differences in language, education, business practices, culture, and industrial development". As shown by Johanson and Wiedersheim-Paul (1975), psychic distance is correlated to distance as often "nearer" countries are geographically close, however counter example exists: England and Australia, albeit very far from each other, are very close countries in term of psychic distance, USA and Cuba are geographically close but are not culturally close in terms of psychic distance.

Zhu and Yang (2004) constructed a psychic distance variable, including geographic distance, common language, development level and common membership with equal weights for each dimension. The dependent variable is a 'crisis index' constructed as a weighted average of the percentage depreciation of country $i$ 's exchange rate and percentage loss in the country's international reserves over a certain time interval. They studied contagion phenomena from December 1994 for the Mexican crisis, July 1997 for the Asian crisis, August 1998 for the Russian crisis, and January 1999 for the Brazilian crisis. The crisis index is constructed using the intervals 1994M11 (November 1994; same interpretation afterwards)—1995M4, 1997M5-1997M10, 1998M7-1998M10 and 1998M12-1999M2 for the four crises respectively. They found that the so constructed psychic distance explanatory variable was negatively and very significantly related to the crisis index, on every crisis. However, the study did not comment on the predictive power that their psychic index may have for an oncoming crisis.

A more extensive definition of psychic distance, is presented by Dow and Karunaratna (2006). A website by Dow gives data for the following psychic distance variables: languages, religions, 
industrial development, levels of education and political systems. See Table 2. Contrary to the research of Bergamo and Pizzi (2014) no corrections are made for any of the factors even though some of them might change over time because it is decided to keep the values as they were intended in the first place. Some indicators could be argued to be time-invariant as changes happen only over a long period of time, such as Language, Religion or even Education; most of the other indicators are taken at a fix point in time even though they are not time-invariant. As pointed out by Bergamo and Pizzi (2014), some indicators may change, especially in developing countries. However, as will be seen in the next section, the majority of countries in the sample for the current research are developed countries. Therefore, the variables of psychic distance used in this research are:

$$
\begin{aligned}
& P D_{L A N G}: \text { differences in languages } \\
& P D_{R E L I G}: \text { differences in religions } \\
& P D_{I N D U S}: \text { differences in industrial development } \\
& P D_{E D U}: \text { differences in levels of education } \\
& P D_{D E M O} \quad: \text { differences in Degree of democracy }
\end{aligned}
$$

\begin{tabular}{|c|c|}
\hline$P D_{L A N G}$ & $\begin{array}{l}\text { This factor is made of three indicators. } \\
\text { The difference between the major languages of country } i \text { and } j \text {. } \\
\text { The incidence of country } i \text { major language on country } j \text {. } \\
\text { The incidence of country } j \text { major language on country } i \text {. }\end{array}$ \\
\hline$P D_{R E L I G}$ & $\begin{array}{l}\text { This factor is made of three indicators. } \\
\text { The difference between the dominant religions of country } i \text { and } j \text {. } \\
\text { The incidence of country } i \text { dominant religion on country } j \text {. } \\
\text { The incidence of country } j \text { dominant religion on country } i \text {. }\end{array}$ \\
\hline$P D_{I N D U S}$ & $\begin{array}{l}\text { This factor is made of ten industrial indicators such as the difference in GDP, in energy } \\
\text { consumption, in number of cars, in percentage of urban population, in percentage of } \\
\text { non-agricultural labour, etc... }\end{array}$ \\
\hline$P D_{E D U}$ & $\begin{array}{l}\text { This factor is made of three indicators. } \\
\text { The difference between the percentage of literate adults of country } i \text { and } j \text {. } \\
\text { The difference between the percentage of population in 2nd level education in country } i \text { and } j \text {. } \\
\text { The difference between the percentage of population in 3rd level education in country } i \text { and } j \text {. }\end{array}$ \\
\hline$P D_{D E M O}$ & $\begin{array}{l}\text { This factor is made of four indicators. } \\
\text { The difference in the "POLCON V scale" between countries } i \text { and } j \text {. } \\
\text { The difference in the "Modified POLITY IV scale" between countries } i \text { and } j \text {. } \\
\text { The difference in the "Freedom House Political Rights scale" between countries } i \text { and } j \text {. } \\
\text { The difference in the "Freedom House Civil Liberties scale" between countries } i \text { and } j \text {. }\end{array}$ \\
\hline
\end{tabular}

Dow gives further information on those variables as shown on the Table 2 below.

Moreover, the variables are compounded into a single factor of psychic distance named $P D_{I N D E X}$.

Table 2. Psychic distance factors. Source: DDow website.

\subsection{Correlation of Real Effective Exchange Rates Returns}

As explained by Darvas (2012), the nominal effective exchange rate is calculated as the geometrical weighted average of the classic nominal exchange rates between the country under research and one of the country of the basket.

$$
N E E R=\prod_{i=1}^{N} S(i)_{t}{ }^{w(i)} \quad \text { with } \quad \begin{aligned}
& N \text { : the number of countries in the basket } \\
& S(i)_{t}: \text { the nominal exchange rate } \\
& w(i): \text { the weight of the trading partner }
\end{aligned}
$$

For instance, the NEER of France in 2016 would be:

$$
N E E R_{\text {France }_{2016}}=S(\text { Country } 0)_{2016}^{w(\text { Country } 0)}+\ldots+S(\text { Country } N)_{2016}^{w(\text { Country } N)}
$$


Then the real effective exchange rate is based on the nominal effective exchange rate with the addition of weights based on consumer price indices. The real effective exchange rate is more often use in the literature than the nominal one because it captures inflation.

$$
R E E R_{t}=\frac{N E E R_{t} * C P I_{t}}{C P I_{t}^{f o r e i g n}}=\frac{N E R R_{t} * C P I_{t}}{\prod_{i=1}^{N} C P I(i)_{t}^{w(i)}}
$$

where $C P I_{t}$ is the consumer price index of the country studied, $N E E R_{t}$ is the nominal effective exchange rate of the country under research and $C P I_{t}^{f o r e i g n}$ is the geometrical weighted average of the consumer price indices of the trading partners in the basket used. For instance, the REER of France in 2016 would be:

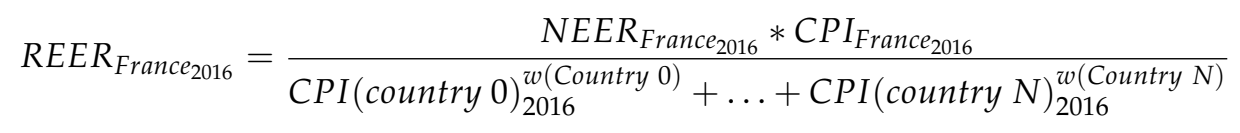

As it can be seen, the weights are time-invariant. Some authors argue that since the composition of foreign trade is time-varying so should the weights; however Darvas (2012) gives a counter example were time-varying weights gives anomalies in the long run which is why time-invariants weights are relevant.

Real exchange rate returns are simply the difference between the logarithm of the month $T$ and month $T-1$ real exchange rate. The usage of returns is justified by the research of Bayoumi et al. (2007) which use returns and by other authors such as Rimarcik (2006) who pointed out that returns are more statistically relevant. The return simply represents the increase or decrease in the real effective exchange rates during a month. Finally, the correlation of real effective exchange rates returns, as used by Bayoumi et al. (2007) is simply computed as a 12-month rolling correlation with a 1-month step between each correlation. The correlation represents the intricacy of the real effective exchange rates between each country pairs. Furthermore, using the correlation coefficient as a dependent variable helps in assessment of the effect of the cultural variables: if the effect is negative for instance, as it is expected to be, then the correlation of real effective exchange rates will decrease when the cultural distance increases. This would mean that the link between farther countries is weaker since their exchange rates are less correlated, and that the contagion effect is overall weaker.

In conclusion, the principal gap in research is that while measures of geographical and psychic distance have been used previously as explanatory variables to investigate correlations in real exchange rates, these distance measures have not been separately studied for their effect. The methodology in this research develops an alternative model specification to capture geographical, psychic and cultural factors.

\section{Data and Methodology}

In this section, a model is specified, data sources and methodological issues are explained.

\subsection{Model Specification}

Looking at the gaps in previous research, the model specified for the current research has the correlation of real exchange rate returns as the dependent variable with geographic distance, cultural factors (Hofstede) and psychic distance as below:

$$
\operatorname{Corr}\left(\operatorname{REER}_{i}, \text { REER }_{j}\right)_{t}=\beta_{0}+\beta_{1} * \ln \left(\text { Distance }_{i, j}\right)+\beta_{2} * \operatorname{HOF}_{I N D E X_{i, j}}+\beta_{3} * \operatorname{PD}_{I N D E X_{i, j}}+u_{0, t}
$$

where $\operatorname{Corr}\left(R E E R_{i}, R E E R_{j}\right)_{t}$ is the correlation between the returns of real effective exchange rates of the countries $i$ and $j$ at the time $t, \beta_{0}$ is the intercept, Distance $e_{i, j}$ is the geographic distance between country $i$ and $j, H O F_{I N D E X_{i, j}}$ is the compound Hofstede index between country $i$ and $j, P_{I N D E X_{i, j}}$ is the compound Psychic distance index between country $i$ and $j$ and $u_{0, t}$ the error term. 


\subsection{Data Sources}

\subsubsection{Geographic Distance}

The gravitation model approach often calls for the usage of the kilometric version of distance. For this variable, the great circle distance between the latitude and longitude of the cities with the most habitants for each country pairs, is used, as there are 30 countries in the sample for the current research. The great-circle distance is correct within $0.5 \%$ (Navy 1959) and its computation is as follows:

$$
\begin{aligned}
& G C D=\operatorname{acos}\left[\cos \left(t_{\text {rad }}\left(90-l a t_{1}\right)\right) * \cos \left(t o_{\text {rad }}\left(90-l a t_{2}\right)\right)\right. \\
& \left.\quad+\sin \left(t o_{\text {rad }}\left(90-l a t_{1}\right)\right) * \sin \left(t_{\text {rad }}\left(90-l a t_{2}\right)\right) * \cos \left(\text { to }_{\text {rad }}\left(\text { lon }_{1}-\text { lon }_{2}\right)\right)\right] * 6371
\end{aligned}
$$

where GCD is the great circle distance, $t_{\text {rad }}$ is a function to turn degrees into radians, lat $_{1}$ and lat $_{2}$ are the latitudes of country 1 and country 2 in degrees, lon 1 and lon 2 are the longitudes of country 1 and country 2 and 6371 is the radius of earth (approximation).

\subsubsection{Hofstede Factors}

The data for the Hofstede factors variables was taken from the website of Hofstede (2017). Those figures were divided in six factors which are power distance, individuality, masculinity, uncertainty avoidance, long term orientation and indulgence. Data is missing on the last two factors for some countries and these countries were left out. The data for each factor was giving a figure for each country. Therefore, it didn't represent a difference between countries but only a level for each country. Similarly, a composite index as expressed by (Kogut and Singh 1988) has been utilized:

$$
\text { HOFindex }_{j k}=\frac{\left(\sum_{i=1}^{6} \frac{\left(X_{i j}-X_{i k}\right)^{2}}{V_{i}}\right)}{6}
$$

In this equation, $X$ represents the factor, $i$ is the factor name (Power distance, $\ldots$ ), $j$ is the country 1 and $k$ the country 2 and $V_{i}$ is the variance for the factor $i$. For example:

$$
\text { HOFindex }_{\text {France }, U S A}=\frac{\left(\frac{\left(\text { HOF }_{P D I}\right. \text { france }}{\left.V_{P D I}-H O F_{P D I U S A}\right)^{2}}+\ldots+\frac{\left(\text { HOF }_{\text {Indul }_{\text {France }}}-H O F_{\text {Indul }_{U S A}}\right)^{2}}{V_{\text {Indul }}}\right)}{6}
$$

Therefore, the higher the HOF the higher the difference between two countries. In this case, the farthest countries were Japan and Sweden whereas the closest were Australia and the United States.

This is illustrated in Table 3.

Table 3. Example of the closest and farthest countries in our sample in term of a compound Hofstede index. Source: Authors' work.

\begin{tabular}{cccc}
\hline Closest Countries & HOF $_{\text {INDEX }}$ & Farthest Countries & HOF $_{\text {INDEX }}$ \\
\hline Australia \& United States & 0.210126197 & Japan \& Sweden & 45.32279963 \\
Germany \& Switzerland & 0.865841059 & Japan \& Norway & 41.16127764 \\
Canada \& United States & 0.905343945 & Australia \& South Korea & 7.205062154 \\
\hline
\end{tabular}

\subsubsection{Psychic Distance}

The data for the psychic distance variable was taken from the website of Douglas Dow (Ddowresearch 2017). Psychic distance was divided into five factors which are languages, religions, industrial development, level of education and political systems (which is made of two sub-factors: degree of democracy and political ideology). The data for each factor was giving a figure for each country pairs (120 countries which makes 7140 unique pairs). The number always represent a 'distance' 
between two countries. In accordance with Dow and Ferencikova (2007) and Kogut and Singh (1988) the following composite index was devised:

$$
\text { PDindex }_{j}=\frac{\left(\sum_{i=1}^{5} \frac{\left(X_{i j}\right)^{2}}{V_{i}}\right)}{5}
$$

In this equation, $X$ represents the factor, $i$ is the factor name (Language, $\ldots$ ),$j$ is the country pair and $V_{i}$ is the variance for the factor $i$. For example:

$$
\text { PDindex } \text { France-USA }=\frac{\left(\frac{P D_{\text {Language }}^{2} \text { France-USA }}{V_{\text {Language }}}+\ldots+\frac{P D_{\text {Indus France-USA }}^{2}}{V_{\text {Indus }}}\right)}{5}
$$

Therefore, the higher the $P D_{I N D E X}$ the higher the differences between two countries. For information, the more estranged countries in term of $P D_{I N D E X}$ in this research are the United States and India. Inversely, the lower the $P D_{I N D E X}$, the lower the difference between two countries. For information, the closest countries in term of $P D_{I N D E X}$ in the current research are the United Kingdom and Sweden. This data is summarised in Table 4.

Table 4. Example of the closest and farthest countries in the sample in term of psychic distance. Source: Authors' work.

\begin{tabular}{cccc}
\hline Closest Countries & PD $_{\text {INDEX }}$ & Farthest Countries & PD $_{\text {INDEX }}$ \\
\hline Sweden \& United Kingdom & 0.078218809 & Canada \& India & 6.738295411 \\
Belgium \& United Kingdom & 0.081189909 & India \& United States & 7.077908151 \\
Belgium \& Sweden & 0.08386957 & China \& United States & 7.205062154 \\
\hline
\end{tabular}

\subsubsection{Real Effective Exchange Rates}

The data for the real effective exchange rates is taken from the Bruegel database for two reasons: first this database contains monthly real effective exchange rates for 153 countries and annual real effective exchange rates for 178 countries which is broader than most common databases such as the World Bank or the OECD. Second, the real effective exchange rate calculated is constantly updated, giving data up to November 2017 (Darvas 2017). From this data real exchange rate returns are computed by taking the natural logarithms:

$$
\text { REER return } n_{i}=\ln \left(\frac{\text { REER }_{i}}{\text { REER }_{i-1}}\right)
$$

with $i$ being the current month. As pointed out by Rimarcik (2006), "returns have more suitable statistical properties than rates". Finally, the correlations of the real effective exchange rate returns between each country pair is computed over 12 months, using a monthly period.

\subsubsection{Sample}

Initially, the data available was very vast: 178 countries over 58 years were represented in the real effective exchange rates data from the Bruegel database. The data sample of monthly REER with a basket of 41 countries (Argentina, Australia, Austria, Belgium, Bolivia, Canada, Chile, Colombia, Denmark, Ecuador, Finland, France, Germany, Ghana, Greece, Hungary, Iceland, India, Indonesia, Ireland, Israel, Italy, Japan, Korea, Luxembourg, Mexico, Netherlands, New Zealand, Norway, Philippines, Portugal, South Africa, Spain, Sweden, Switzerland, Taiwan, Turkey, United Kingdom, United States, Uruguay, Venezuela) was examined although a wider basket of 138 countries was available, as the sample spread is for a period 46 years (1970 to 2016). Finally, the period was reduced to 23 years (1993 to 2016) for two reasons: albeit the sample start in 1970, this was only 
the case for a few countries, most of the time the data was only available from 1993. The second reason is that since the first big contagion event that is being examined was in 1994 (Mexican crisis). This resulted in reducing the number of countries from which the largest 30 by market capitalisation were chosen (Australia, Belgium, Brazil, Canada, Chile, China, Colombia, Finland, France, Germany, Hong Kong, India, Indonesia, Italy, Japan, Malaysia, Mexico, Netherlands, Norway, Russia, Saudi Arabia, Singapore, South Africa, South Korea, Spain, Sweden, Switzerland, Thailand, United Kingdom, United States). Other countries are excluded from the sample because of their smaller economy size or because of missing data.

\subsubsection{Estimation}

The EViews program is used to estimate a regression equation on the specified model over the whole sample first: the correlation of real effective exchange rate returns for country pairs in the sample is regressed against the geographic distance (kilometric distance between the most populated cities in each country), the Hofstede cultural factors (perceived distance between countries in terms of power distance, indulgence, long term orientation, masculinity, individuality and uncertainty avoidance), psychic distance (perceived distance between countries in terms of education, religion, language, industry and politics). The data set is generated on a monthly basis for 30 countries over 24 years from 1993 to 2016 and is sorted into a panel form using country pairs and the dates as keys ultimately making 435 cross section over 123,105 observations. Next a rolling regression is run on Eviews to observe the variation of the coefficients over time with a fixed window of 5220 observations (equivalent to 12 months) and a step of 435 observations (equivalent to 1 month), involving 271 regressions. This is summarised in Table 5 .

Table 5. Rolling regression parameters. Source: created by Authors.

\begin{tabular}{ll}
\hline Starting date & 1993M07 \\
Ending date & 2016M12 \\
First regression & From 1993M07 to 1994M06 \\
Last regression & From 2016M01 to 2016M12 \\
Number of regressions & 12 per year and only 7 in 1994 which makes 271 regressions. \\
\hline
\end{tabular}

The crisis start dates (Table 6) for examination of the correlations in real exchange rates and variation of the distance coefficients over time are identified from published literature.

Table 6. Crisis start dates. Source: created by Authors.

\begin{tabular}{cc}
\hline Crisis & Starting Date \\
\hline Mexican crisis & December 1994 \\
Asian crisis & July 1997 \\
Russian crisis & August 1998 \\
Dot-com crisis & March 2000 \\
Global financial crisis & August 2007 \\
European debt crisis & October 2009 \\
Russian crisis & December 2014 \\
\hline
\end{tabular}

\section{Regression Analysis and Findings}

This section presents and discusses the findings from the statistical tests over the whole sample and the rolling regression over a 12-month period with a 1-month step between each regression.

\subsection{Regression over the Whole Period}

The regression equation estimated over the whole sample is

$$
\operatorname{Corr}\left(R E E R_{i}, R E E R_{j}\right)_{t}=\beta_{0}+\beta_{1} * \ln (\text { distance })+\beta_{2} * H O F_{I N D E X}+\beta_{3} * P D_{I N D E X}+\mu_{0}
$$


where $\operatorname{Corr}\left(R E E R_{i}, R E E R_{j}\right)$ are the correlations of the returns of real effective exchange rates between country $i$ and country $j ; \beta_{0}$ is the intercept; $\beta_{1}, \beta_{2}$ and $\beta_{3}$ are the parameters to be estimated and $\mu_{0}$ is the error term.

The first date on the sample is June 1993 and the last date is December 2016. The data set is of 30 countries over 24 years from 1993 to 2016 and is sorted into a panel form using country pairs and the dates as keys ultimately making 435 cross section over 123,105 observations. The pooled and fixed effects panel data model were estimated and the fixed effects model is chosen (after redundant fixed effects test), the output of which is given in Table A1 in Appendix A: The main features of the estimations are given in Tables 7 and 8.

Table 7. Test for redundant fixed effects. Source: Authors' work.

\begin{tabular}{cccc}
\hline Effects Test & Statistic & d.f & Prob. \\
\hline Period F & 1.984007 & $(282.123)$ & 0.0000 \\
Period Chi-square & 559.519360 & 282 & 0.0000 \\
\hline
\end{tabular}

The equation estimated with fixed effects is:

Table 8. Explanatory variables and estimates of coefficients. Source: Authors' work.

\begin{tabular}{ccc}
\hline Fixed Effects Model & $\begin{array}{c}\text { Prob of F-Statitic } \\
\text { Value of the Coefficient }\end{array}$ & $\mathbf{0 . 0 0 0}$ \\
Pariable & 0.813613 & 0.000 \\
C (intercept) & -0.070981 & 0.000 \\
$\ln ($ Distance $)$ & -0.006718 & 0.000 \\
HOF INDEX & -0.037632 & 0.000 \\
\hline$D_{I N D E X}$ & \\
\hline
\end{tabular}

It can be observed that all the explanatory variables are significant and have a negative impact on the correlation of real exchange rate returns. This result was expected as countries which are further away have less correlation of real effective exchange rates returns.

\subsection{Overall Significance}

The $p$-value of the F-statistic is under $5 \%$ meaning that the model is overall valid with at least some significant coefficients for the explanatory variables.

Furthermore, we can see that, overall, the higher the distance between the countries, in all considered terms, the lower the correlation between the real effective exchange rate returns of the countries. This is in accordance with both previous literature and the gravitational model itself where links are weaker when distance is greater. For instance, the research of Bergamo and Pizzi (2014), albeit looking at foreign direct investments, also found that cultural aspects of distance have negative effects. Overall, it was expected that geographic distance had a negative impact on the correlation as it was shown by most studies on geographic distance and trade (in broad terms). The work of Bayoumi et al. (2007) on a different composition of the distance variable also found a significant negative coefficient.

The implications of the value of the distance coefficients is next individually interpreted:

\subsection{Geographic Distance}

The table shows that the coefficient of geographic distance is negative and statistically significant at the $5 \%$ level of significance. An increase of $1 \%$ in geographic distance results in a $0.070981 \%$ decrease in the correlation of real effective exchange rate returns. Furthermore, this coefficient is the largest in absolute value of the three distance coefficients. This may be explained by the overall decrease in the importance of geographic distance for all trade and market operations because of the internet, decrease in fees and trading costs. 


\subsection{Cultural Distnce (HOF INDEX)}

The table shows that the coefficient of the Hofstede index (cultural distance) is negative and statistically significant at the $5 \%$ level of significance. An increase of 1 unit of the $H O F_{I N D E X}$ results in a 0.006718 decrease in the correlation of real exchange rate returns. Furthermore, this coefficient is the lowest in absolute value of the three distance coefficients.

\subsection{Psychic Distance (PD INDEX $)$}

The table shows that the coefficient of $P D_{I N D E X}$ (psychic distance) is negative and statistically significant at the $5 \%$ level of significance. An increase of 1 unit of the $P D_{I N D E X}$ results in a 0.037632 decrease in the correlation of real effective exchage rate returns. As indicated earlier, this could be due to the broader nature of psychic distance factors when compared to Hofstede factors which are narrower and based on a survey of employees.

Behavioral finance has shown previously that investors can be affected by home-bias and can choose to forgo profitable investments overseas because of the intervening higher distance. Psychic distance and Cultural distance on the other hand are more virtual concepts. In this research, the coefficients of these alternative concepts of distance show similar effects as the geographic distance coefficients but with stronger effects. This would suggest that geographic distance is not the most important factor as to how a country sees itself with respect to another. The importance of psychic distance has been documented in another context (called the psychic distance paradox): O'grady and Lane (1996) found out, using psychic distance, that managers tend to invest or start a new venture in countries that they feel are closer. However, the paradox is that most of those ventures actually failed.

\subsection{Rolling Regression}

A rolling regression is essentially a regression that is repeated over different periods of time. A fixed window rolling regression is chosen for this research, details of which are given in Table 9 below to examine the variations in the value of the distance coefficients over time, as did Bayoumi et al. (2007), albeit their variables were different.

Table 9. Rolling regression parameters. Source: prepared by Authors.

\begin{tabular}{ll}
\hline $\begin{array}{l}\text { Fixed window rolling } \\
\text { regression }\end{array}$ & $\begin{array}{l}\text { The window is the number of observation in each regression (for instance the } \\
5220 \text { observations to make 12-months) and the step is how far the window is } \\
\text { moved between each regression (for instance 435 observations to make 1 month). }\end{array}$ \\
\hline Starting date & 1993M07 \\
\hline Ending date & 2016M12 \\
\hline First regression & From 1993M07 to 1994M06 \\
\hline Last regression & From 2016M01 to 2016M12 \\
\hline Numberof regressions & 12 per year and only 7 in 1994 which makes 271 regressions. \\
\hline
\end{tabular}

As earlier stated, in Table 6, the crisis periods for examination of the correlations in real exchange rates and variation of the distance coefficients over time are identified as (stated once again in Table 10):

Table 10. Crisis' starting dates of the worst recent crisis. Source: Authors' work.

\begin{tabular}{cc}
\hline Crisis & Starting Date \\
\hline Mexican crisis & December 1994 \\
Asian crisis & July 1997 \\
Russian crisis & August 1998 \\
Dot-com crisis & March 2000 \\
Global financial crisis & August 2007 \\
European debt crisis & October 2009 \\
Russian crisis & December 2014 \\
\hline
\end{tabular}


At first, the average of real exchange rate returns correlation over time is examined, and then the rolling coefficients of geographic, cultural (Hofstede) and psychic distance.

\subsection{Average of Correlation of Real Exchange Rate Returns over Time}

The first plot below is of the average correlation of real effective exchange rate returns computed using a 12-month window and a 1-month step, in the sample (1193M07 to 2016M12).

Data on correlations of Real Effective Exchange returns are in Supplmentary B (see Supplementary Material). The average correlation of the real effective exchange rate returns (Figure 1) is rather weak, reaching a peak of $12.35 \%$ in November 2013 and a lowest point of $2.6 \%$. There is an overall upward trend which is coherent with the global tightening of currencies and the increased trade relationship between countries. The average is however close to zero most of the time, correlation tends to increase before a crisis event. Bayoumi et al. (2007) who also studied this variable (over a different period of time) had similar results. They argued that this is probably because most of the countries in the sample intervened in their currency market to stabilize the rates first and then gave more exchange rate freedom after crisis outbreaks.

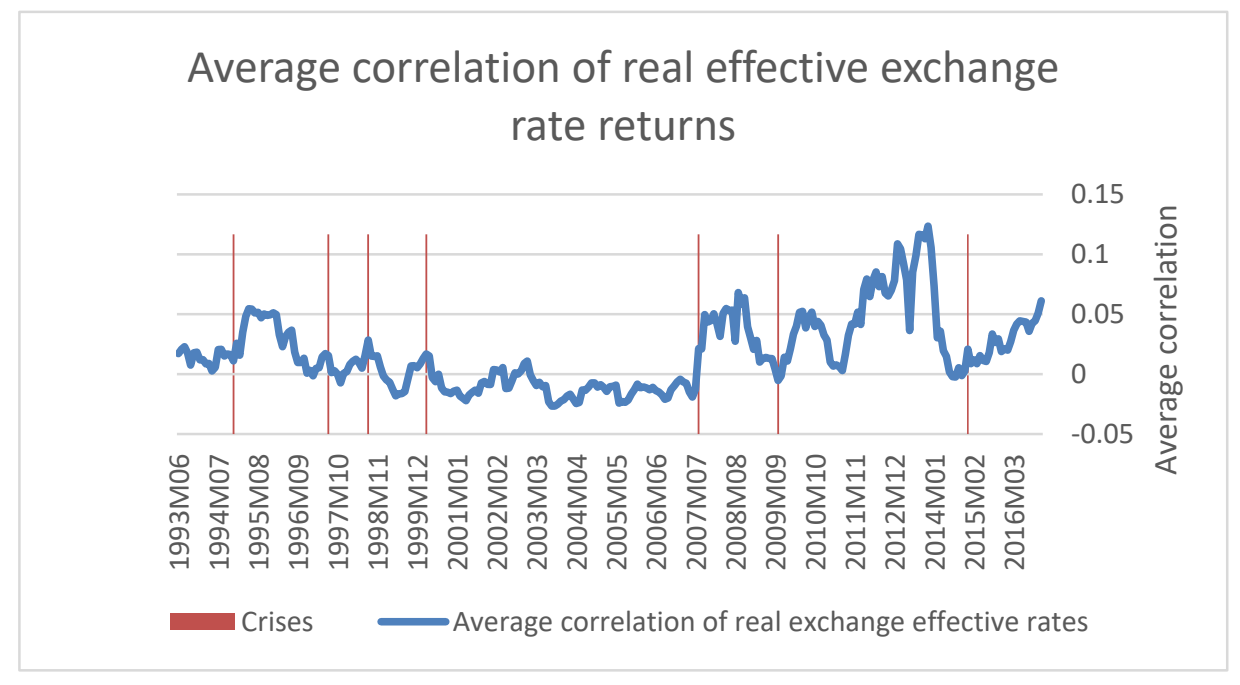

Figure 1. Average correlation of real effective exchange rate returns. Details are available in Supplmentary B. Source: Authors' work.

The rolling coefficients of distance indices and $p$-values as estimated from the Rolling regression are given in Supplmentary C (see Supplementary Material).

\subsection{Rolling Coefficients of Geographic Distance}

The rolling coefficients of geographic distance (Figure 2) varies from a maximum of -0.027995828 to a minimum of -0.129347146 over the entire sample period (1993M07 to 2016M12). It is also to be noted that the rolling coefficients are significant ( $p$ value $<1.0 \%$ in the entire period). The value of the coeffcient rises before a crisis, and after the crisis tends to fall. Apart for the dot-com crisis of 2000, the value of the geographic distance coefficient in subsequent crises does not fall probably because of the growing relevance of other distance variables.

\subsection{Rolling Coefficients of Cultural Distance (Hofstede Index)}

The rolling coefficient of the cultural distance (Hofstede index; Figure 3) varies from a maximum of -0.00169315 and a minimum of -0.013767782 over the entire sample period (1993M07 to 2016M12). It is also to be noted that the rolling coefficients are mostly highly significant ( $p$ value $<1.0 \%$ in the entire period). A sharp increase is noticed just before the dot-com crisis of 2000. For most of the crisis indicated in the graph, an increase in value can be observed to the run-up to a crisis event (before the 
Asian crisis, the dot-com crisis, the European debt crisis and the recent Russian crisis). The run-up to a crisis event may indicate periods of 'positive contagion' where investors 'herd' towards an investment. Moreover, for most of the crisis, an immediate fall of the coefficient can be observed (after the Mexican crisis and the dot-com crisis particularly). The fall in values after the crisis indicate periods of 'negative' contagion where investors herd away from the bubble.

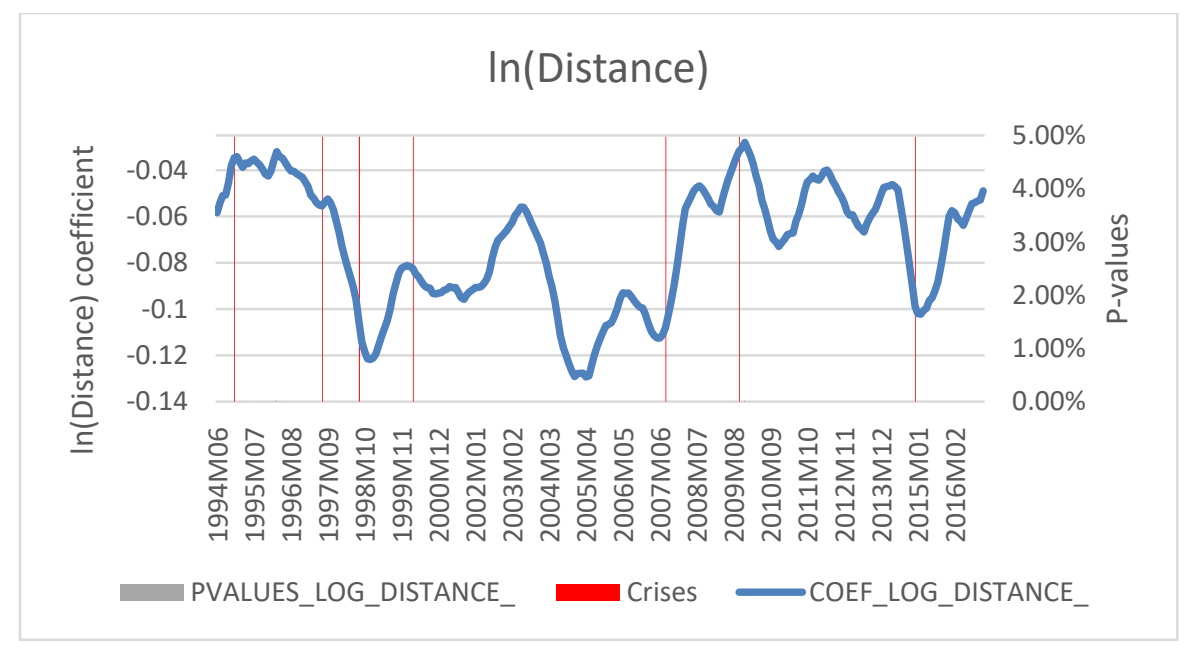

Figure 2. Coefficients and $p$-values for the $\ln$ (Distance) variable of the rolling regression. ( $p$-values are too small to be seen and are available in the Supplmentary C). Source: Authors' work.

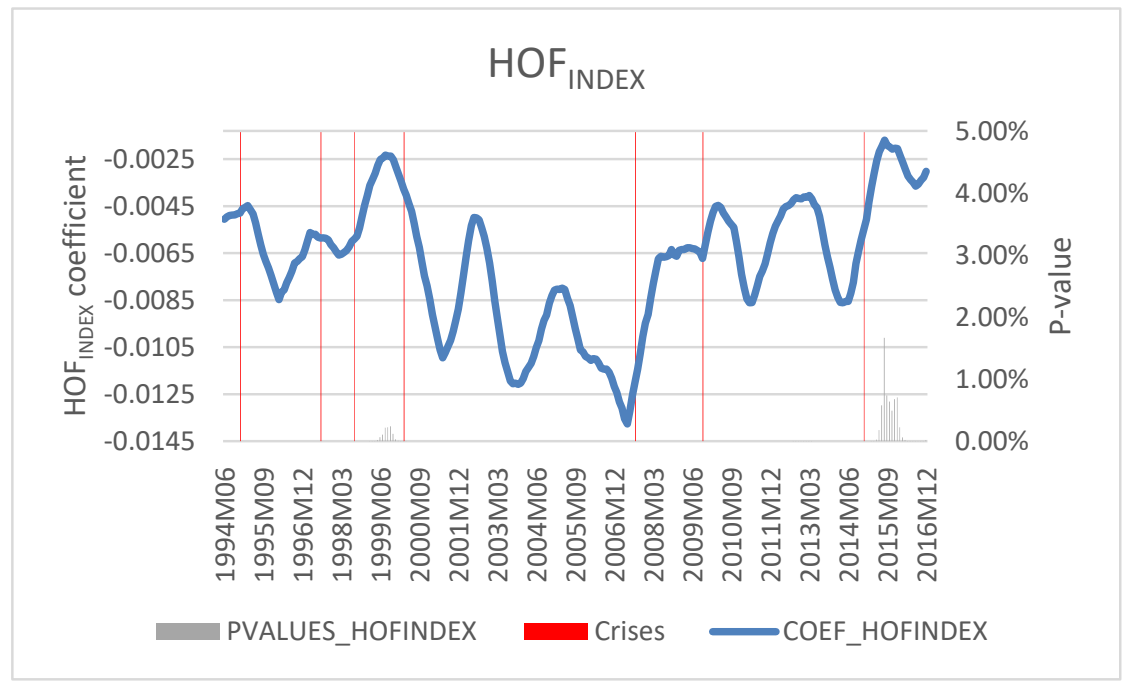

Figure 3. Evolution of the coefficient and $p$-values for the HOF INDEX variable of the rolling regression. $p$-values are available in the Supplmentary C. Source: Authors' work.

\subsection{Rolling Coefficients of Psychic Distance (PDINDEX)}

The rolling coefficient of psychic distance ( $P D_{I N D E X}$; Figure 4) varies from a maximum of 0.009325894 to a minimum of -0.100999054 over the entire sample period ( $1993 \mathrm{~m} 07$ to $2016 \mathrm{~m} 12)$. In the case of psychic distance, several comments could be made. First, most of the early results, before 2001 are often not statistically significant as the $p$-values are well above $5 \%$. Second, many similarities can be observed between this plot and the Hofstede variable's plot. This is probably due to the similarities between the two variables. Finally, the effect seen earlier of peaks before crisis is still present.

The most important overall result that can be observed is that the distance variables tend to be a good proxy for interdependence between the economies. Moreover, the three variables tend to increase (e.g., return to zero) before a crisis. Since all the coefficient are negative, an increase is actually 
a representation of a weakening of the relationship between the variables. In simple terms, all the variables of distance examined in this research show that they become meaningless before a crisis. Furthermore, the lower importance of distance seems to support that cultural and psychic variables are essential to grasp a more complete idea of distance in gravitational models.

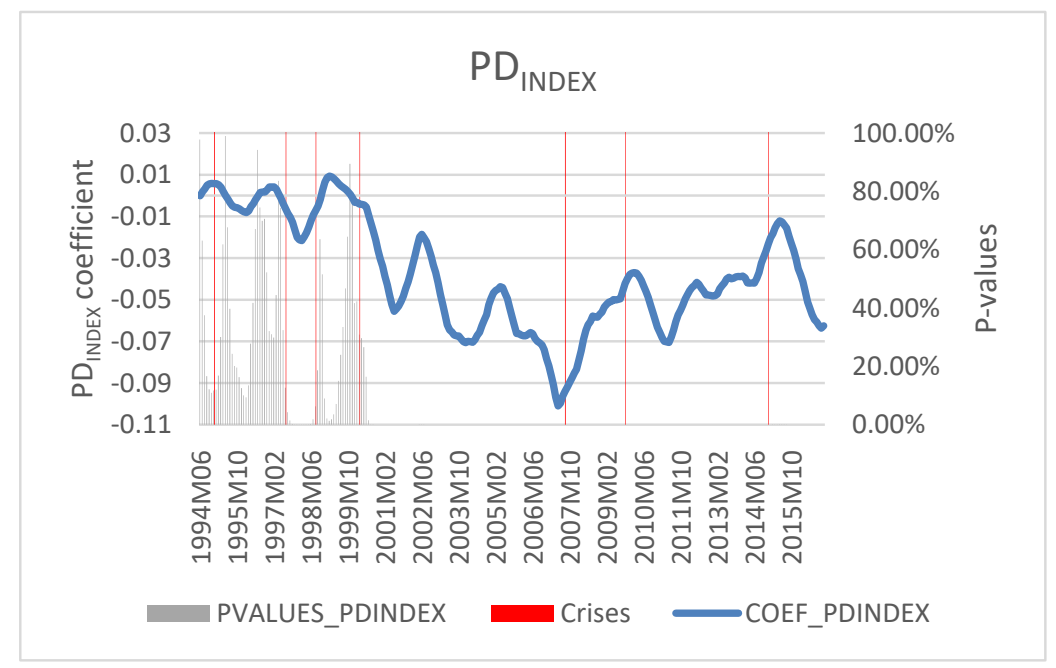

Figure 4. Coefficients and $p$-values for the $P D_{I N D E X}$ variable of the rolling regression. Details of $p$-values are available in Supplmentary C. Source: Authors' work.

This would indicate a behavioural trend that investors tend to forget the distance and herd to perceived profitable opportunities. Then, when the bubble bursts, geographical, cultural and psychic distance become important factors again. Distance factors can then be a leading indicator for an oncoming crisis.

\section{Conclusions}

The aim of this research was to ascertain whether geographic distance, cultural factors and psychic distance have any effect on the correlation of real effective exchange rate returns, and if so, to examine the evolution of the coefficients pre and post contagion towards identifying them as leading indicators of an oncoming crisis.

The current research has found affirmation on both the issues. Based on monthly data from a sample of 30 countries over 24 years, the investigation showed geographic, cultural and psychic variables have a significant negative impact on the correlation of real effective exchange rate returns. In other words, countries that are closer and feel closer are likely to have a high correlation between their exchange rates returns. The impact of the variables of distance tend to get closer to zero before crisis events and points to the importance of cultural and psychic distance in addition to geographic distance with cultural factors playing a more important role than others in a lead to a crisis event. Distance factors thus evidence typical values before and after a crisis event in periods of 'positive contagion' and 'negative contagion'.

This research has developed alternative approaches to contagion anaysis and prediction to that of Sachs et al. (1996), Kaminsky and Reinhart (2000) and to that of Zhu and Yang (2004) and Bayoumi et al. (2007) by using a modified version of the gravitational model and a broader specification of the independent variables thereby assessing the separate impacts of geographic distance, psychic distance and cultural factors to assess their predictive power. Utilising psychic factors via the index compiled by Dow and Karunaratna (2006), and Hofstede (1984) factors not before used in this way, the current research has shown the advantages of conceptualising alternative measures of distance and their additional explanatory power, leading to a crisis event. The practical use of this model is for policy makers who can jointly look at all distance factors (geographic, cultural and 
psychic) toward identifying an oncoming crisis event and contagion, and enable them to take timely appropriate measures toward stabilising economic conditions.

\section{Limitations and Future Research}

The limitations of the current research are that it has studied the relevance of distance factors alone (geographic, cultural and psychic) in their relationship with the correlation of real exchange rate returns between countries. There may be other variables with equal or better explanatory power. Another possible limitation is that presented by available data; not all the countries and all the dates are in the sample. Finally, the reality is that cultural distance and psychic distance are conceptualised within a set of pre-defined constructs and more appropriate conceptualisations (yet to be discovered) may be possible in future research.

Data sources: Real effective exchange rates:http://bruegel.org/wp-content/uploads/imported/publications / 120315_ZD_REER_WP_01.pdfGeographic index: http://www.geosats.com/0x2circ.html; http://www.indo. com/distance/Hofstede index: https://www.hofstede-insights.com/models/national-culture/Psychic distance: https://sites.google.com/site/ddowresearch/home/scales

Supplementary Materials: The following are available online at http:/ /www.mdpi.com/2227-7072/6/4/85/s1. Author Contributions: The contribution to this article is distributed as follows: J.C. 50\%, V.S. $50 \%$.

Acknowledgments: The authors acknowledge the pioneering work in this field in the publications of Zhu and Yang (2004) and Bayoumi et al. (2007) and of course, the work of others they have referred to in their work.

Conflicts of Interest: The authors declare no conflict of interest.

\section{Appendix A}

Table A1. Regression Results.

\begin{tabular}{|c|c|c|c|c|}
\hline \multicolumn{5}{|c|}{$\begin{array}{l}\text { Roll: } \\
\text { Roll type: Fixed window } \\
\text { Specification: EQ1 } \\
\text { Estimation command: ROLL (F, WINDOW = 5220, STEP = 435) @ EQ1 }\end{array}$} \\
\hline $\begin{array}{l}\text { Number of subsamples: } \\
\text { Number of coefficients: } \\
\text { Window size: } \\
\text { Step size: }\end{array}$ & & \multicolumn{3}{|l|}{$\begin{array}{l}271 \\
4 \\
5220 \\
435\end{array}$} \\
\hline \multicolumn{5}{|c|}{$\begin{array}{l}\text { Full sample estimation results: } \\
\text { Dependent Variable: CORR } \\
\text { Method: Panel Least Squares } \\
\text { Date: } 01 / 14 / 18 \text { Time: } 11: 45 \\
\text { Sample: } 1 \text { 123,105 } \\
\text { Periods included: } 435 \\
\text { Cross-sections included: } 283 \\
\text { Total panel (balanced) observations: } 123,105\end{array}$} \\
\hline Variable & Coefficient & Std. Error & $\mathrm{t}$-Statistic & Prob. \\
\hline $\begin{array}{l}\text { C } \\
\text { LOG(DISTANCE) } \\
\text { HOFINDEX } \\
\text { PDINDEX }\end{array}$ & $\begin{array}{l}0.813613 \\
-0.07098 \\
-0.00672 \\
-0.03763\end{array}$ & $\begin{array}{l}0.01248 \\
0.001496 \\
0.000161 \\
0.000848\end{array}$ & $\begin{array}{l}65.19142 \\
-47.4529 \\
-41.7483 \\
-44.3518\end{array}$ & $\begin{array}{l}0 \\
0 \\
0 \\
0\end{array}$ \\
\hline \multicolumn{5}{|c|}{ Effects Specification } \\
\hline \multicolumn{5}{|c|}{ Cross-section fixed (dummy variables) } \\
\hline $\begin{array}{l}\text { R-squared } \\
\text { Adjusted R-squared } \\
\text { S.E. of regression } \\
\text { Sum squared resid } \\
\text { Log likelihood } \\
\text { F-statistic } \\
\text { Prob (F-statistic) }\end{array}$ & $\begin{array}{l}0.074747 \\
0.0726 \\
0.458211 \\
25,786.76 \\
-78,461 \\
34.81395 \\
0.0000\end{array}$ & \multicolumn{2}{|c|}{$\begin{array}{l}\text { Mean dependent var } \\
\text { S.D. dependent var } \\
\text { Akaike info criterion } \\
\text { Schwarz criterion } \\
\text { Hannan-Quinn criter. } \\
\text { Durbin-Watson stat }\end{array}$} & $\begin{array}{l}0.017264 \\
0.475808 \\
1.279347 \\
1.301931 \\
1.286137 \\
1.675228\end{array}$ \\
\hline
\end{tabular}

(generated by Authors using Eviews 7). 


\section{References}

Baig, Taimur, and Ilan Goldfajn. 2002. Monetary Policy in the Aftermath of CurrencyCrises: The Case of Asia. Review of International Economics 10: 92-112. [CrossRef]

Bayoumi, Tamim, Giorgio Fazio, Manmohan Kumar, and Ronald MacDonald. 2007. Fatal attraction: Using distance to measure contagion in good times as well as bad. Review of Financial Economics 16: 259-73. [CrossRef]

Beckerman, Wilfr. 1956. Distance and the Pattern of Intra-European Trade. The Review of Economics and Statistics 38: 31-40. [CrossRef]

Bergamo, Gianni, and Claudio Pizzi. 2014. Foreign direct investment and psychic distance: A graviy model approach. Rivista Italiana di Economia, Demografia e Statistica 68: 167-74.

Calvo, Guillermo A. 2004. Contagion in Emerging Markets: When Wall Street is a Carrier. In Latin American Economic Crises. Edited by E. Bour, D. Heymann and F. Navajas. International Economic Association. London: Palgrave Macmillan.

Calvo, Guillermo A., and Carlos A. Vegh. 1999. Inflation Stabilization and BOP Crises in Developing Countries. Working Paper No. 6925. Cambridge, MA, USA: NBER.

Calvo, Guillermo A., and Enrique G. Mendoza. 1999. Regional Contagion and the Globalization of Securities Markets. Working Paper No. 7153. Cambridge, MA, USA: NBER.

Corsetti, Giancarlo, Marcello Pericoli, and Massimo Sbracia. 2001. Correlation Analysis of Financial Contagion: What One Should Know Before Running a Test. Discussion Paper, No. 822. New Haven, CT, USA: Yale Economic Growth Center.

Corsetti, Giancarlo, Marcello Pericoli, and Massimo Sbracia. 2005. 'Some contagion, some interdependence': More pitfalls in tests of financial contagion. Journal of International Money and Finance 24: 1177-99. [CrossRef]

Darvas, Zsolt. 2012. Real Effective Exchange Rates for 178 Countries: A New Database. Working Paper 2012/06. Bruegel. Available online: http://bruegel.org/wp-content/uploads/imported/publications/120315_ZD_ REER_WP_01.pdf (accessed on 15 June 2017).

Darvas, Zsolt. 2017. Dataset. Available online: http://bruegel.org/publications/datasets/real-effective-exchangerates-for-178-countries-a-new-database/ (accessed on 15 June 2017).

Dornbusch, Rudiger, Yung Chul Park, and Stijn Claessens. 2000. Contagion: Understanding How It Spreads. World Bank Research Observer 15: 177-97. [CrossRef]

Dow, Douglas, and Amal Karunaratna. 2006. Developing a multidimensional instrument to measure psychic distance stimuli. Journal of International Business Studies 37: 578-602. [CrossRef]

Dow, Douglas, and Sonia Ferencikova. 2007. The Measurement and Impact of Psychic Distance: Testing a New Scale on FDI in Slovakia. Paper presented at the 33rd European International Business Academy (EIBA) Conference, Catania, Italy, December 13; pp. 13-15. Available online: https:/ / www.researchgate.net/profile/ Douglas_Dow2/publication/237218757_The_Measurement_and_Impact_of_Psychic_Distance_Testing_a_ New_Scale_on_FDI_in_Slovakia/links/566a149908ae1a797e37919f.pdf (accessed on 10 November 2017).

Ddowresearch. 2017. Measures of Psychic Distance Stimuli-Douglas Dow. Available online: https://sites.google. $\mathrm{com} /$ site/ddowresearch/home/scales (accessed on 10 November 2017).

Eichengreen, Barry, Andrew K. Rose, and Charles Wyplosz. 1995. Exchange Market Mayhem: The Antecedents and Aftermath of Speculative Attacks. Economic Policy 21: 249-312. [CrossRef]

Engle, Robert F., Takatoshi Ito, and Wen-Ling Lin. 1990. Meteor Showers or Heat Waves? Heteroskedastic Intra-Daily Volatility in the Foreign Exchange Market. Econometrica 58: 525-42. [CrossRef]

Glick, Reuven, and Andrew K. Rose. 1999. Contagion and trade: Why are currency crises regional? Journal of International Money and Finance 18: 603-17. [CrossRef]

Hofstede, Geert. 1984. Culture's Consequences: International Differences in Work-Related Values. Newbury Park: Sage.

Hofstede, Geert. 2011. Dimensionalizing Cultures: The Hofstede Model in Context. Online Readings in Psychology and Culture 2: 8. [CrossRef]

Hofstede, Geert. 2017. Dataset. Available online: https://www.hofstede-insights.com/country-comparison/ (accessed on 20 November 2017).

Johanson, Jan, and Finn Wiedersheim-Paul. 1975. The internationalization of the firm-Four Swedish cases. Journal of Management Studies 12: 305-23. [CrossRef] 
Johanson, Jan, and Jan-Erik Vahlne. 1977. The internationalization process of the firm: A model of knowledge development and increasing foreign market commitments. Journal of International Business Studies 8: $23-32$. [CrossRef]

Kaminsky, Graciela L., and Carmen M. Reinhart. 2000. On crises, contagion, and confusion. Journal of International Economics 51: 145-68. [CrossRef]

Karolyi, G. Andrew. 2003. Does International Financial Contagion Really Exist? International Finance 6: 179-99. [CrossRef]

King, Mervyn A., and Sushil Wadhwani. 1990. Transmission of volatility between stock markets. Review of Financial Studies 3: 5-33. [CrossRef]

Kumar, Manmohan S., and Avinash Persaud. 2002. Pure Contagion and Investors' Shifting Risk Appetite: Analytical Issues and Empirical Evidence. International Finance 5: 401-36. [CrossRef]

Kogut, Bruce, and Harbir Singh. 1988. The effect of national culture on the choice of entry mode. Journal of International Business Studies 19: 411-32. [CrossRef]

Loungani, Prakash, Ashoka Mody, and Assaf Razin. 2002. The global disconnect: The role of transactional distance and scale economies in gravity models. Scottish Journal of Political Economy 49: 526-43. [CrossRef]

Masson, Paul. 1999. Contagion: Macroeconomic models with multiple equilibria. Journal of International Money and Finance 18: 587-602. [CrossRef]

Moser, Thomas. 2003. What Is International Financial Contagion? International Finance 6: 157-78. [CrossRef]

Navy, Royal. 1959. Admiralty Manual of Navigation, 1; London: Her Majesty's Stationary Office.

O'grady, Shawna, and Henry W. Lane. 1996. The psychic distance paradox. Journal of International Business Studies 27: 309-33. [CrossRef]

Puy, Damien. 2013. Institutional Investors Flows and the Geography of Contagion. EUI Working Paper ECO 2013/06. Fiesole, Italy: Department of Economics, European University Institute.

Ravenstein, Ernst Georg. 1889. The laws of migration. Journal of the Royal Statistical Society 52: 241-305. [CrossRef] Rimarcik, Marián. 2006. Statistical properties of exchange rates. Biatec 14: 6-8.

Rigobon, Roberto. 2002. Contagion: How to measure it? In Preventing Currency Crises in Emerging Markets, 1st ed. Chicago: The University of Chicago Press, pp. 269-334.

Rodrik, Dani. 2008. The real exchange rate and economic growth. Brookings Papers on Economic Activity 2008: 365-412. [CrossRef]

Tinbergen, Jan. 1962. Shaping the World Economy: Suggestions for an International Economic Policy. 1. New York: Twentieth Century Fund.

Sachs, Jeffrey, Aaron Tornell, and Andres Velasco. 1996. Financial Crises in Emerging Markets: The Lessons from 1995. Brookings Papers on Economic Activity, Economic Studies Program. Washington, DC: The Brookings Institution, vol. 27, pp. 147-216.

Xu, Bei. 2008. Co-mouvements extrêmes, interdépendance ou contagion? Une analyse d'après la théorie des valeurs extrêmes, LAREefi, Université Montesquieu Bordeaux IV. Available online: http://www.univorleans.fr/gdre09/articles/XUBei.pdf (accessed on 10 November 2017).

Zhu, Lili, and Jiawen Yang. 2004. The Role of Psychic Distance in Contagion: A Gravity Model for Contagious Financial Crises. Washington, DC: The George Washington University, October.

(C) 2018 by the authors. Licensee MDPI, Basel, Switzerland. This article is an open access article distributed under the terms and conditions of the Creative Commons Attribution (CC BY) license (http://creativecommons.org/licenses/by/4.0/). 